\title{
Short communication: Milk fat composition of 4 cattle breeds in the Netherlands
}

\author{
M. H. T. Maurice-Van Eijndhoven, ${ }^{*} \dagger^{1}$ S. J. Hiemstra, ${ }^{\star} \neq$ and M. P. L. Calus ${ }^{\star}$ \\ *Wageningen UR Livestock Research, Animal Breeding and Genomics Centre, PO Box 65, 8200 AB Lelystad, the Netherlands \\ †Wageningen University, Animal Breeding and Genomics Centre, PO Box 338, $6700 \mathrm{AH}$ Wageningen, the Netherlands \\ $\neq$ Centre for Genetic Resources (CGN), PO Box 65, 8200 AB Lelystad, the Netherlands
}

\section{ABSTRACT}

Milk fatty acid (FA) composition was compared among 4 cattle breeds in the Netherlands: Dutch Friesian (DF; 47 animals/3 farms), Meuse-Rhine-Yssel (MRY; 52/3), Groningen White Headed (GWH; 45/3), and Jersey (JER; 46/3). Each cow was sampled once between December 2008 and March 2009 during the indoor housing season, and samples were analyzed using gas chromatography. Significant breed differences were found for all traits including fat and protein contents, 13 major individual FA, 9 groups of FA, and 5 indices. The saturated fatty acid proportion, which is supposed to be unfavorable for human health, was smaller for GWH (68.9\%) compared with DF (74.1\%), MRY (72.3\%), and JER $(74.3 \%)$ breeds. The proportion of conjugated linoleic acid and the unsaturation index, which are associated positively with human health, were both highest for GWH. Differences in milk fat composition can be used in strategies to breed for milk with a FA profile more favorable for human health. Our results support the relevance of safeguarding the local Dutch breeds.

Key words: milk, fatty acid, cattle breed

\section{Short Communication}

Within the Netherlands different dairy cattle breeds are used for milk production. High emphasis in selection for milk yield, however, has led to an enormous reduction in breed variability. Today, more than $97 \%$ of the milk-recorded population belongs to HolsteinFriesian (HF; CRV, 2009). In general, individual cattle breeds comprise unique genetic variation (European Cattle Genetic Diversity Consortium, 2006); thus, it can be hypothesized that local Dutch breeds comprise some genetic variation that is not present in the HF breed. An important question is to understand if these

Received December 19, 2009.

Accepted October 29, 2010.

${ }^{1}$ Corresponding author: myrthe.maurice-vaneijndhoven@wur.nl genetic resources are related to any unique and valuable characteristics that could be important now or in the future. Unique characteristics can influence directions in selection or allow the assignment of a breed to a special brand product, which is an important tool to maintain native genetic resources characterized by low production levels (Dalvit et al., 2007; Pretto et al., 2009).

Recently, milk quality traits have become increasingly relevant as consumer awareness of healthy diets is growing. In this context, bovine milk is being increasingly recognized as an important source of energy, highquality protein, and essential minerals and vitamins (Heaney, 2000; Neumann et al., 2003; German and Dillard, 2006). However, several studies report negative effects on human health from the consumption of bovine milk (Lock and Bauman, 2004; German and Dillard, 2006; Uauy, 2009). Results from those studies have led to an ongoing debate on the role of milk and dairy products in human health (Palmquist et al., 2006). The diet used in the herd plays a central role in determining the variation of milk fat composition (Palmquist, 2006). Also, a significant part of the variability in fatty acid (FA) composition is genetically determined (e.g., Beaulieu and Palmquist, 1995; Stoop et al., 2008).

The aim of this study was to investigate the differences in individual FA composition in milk of the local cattle breeds Dutch Friesian (DF), Meuse-Rhine-Yssel (MRY), and Groningen White Headed (GWH), and imported Jersey (JER) within the Netherlands.

A total of 190 cows was sampled once during morning milking between December 2008 and March 2009. Samples were treated immediately with $0.03 \%$ (wt/wt) sodium azide to prevent microbiological growth. Cows belonged to 4 breeds: DF (47 samples from 3 farms), MRY (52 samples from 3 farms), GWH (45 samples from 3 farms), and JER (46 samples from 3 farms). The selected farms were of general size ranging from 35 to 120 cows, and the number of sampled animals per herd ranged from 6 to 24. For each breed farmers were asked to select cows that varied in terms of age at calving, parity, stage of lactation, and ancestors. On all farms 
Table 1. Groups of fatty acids and indices

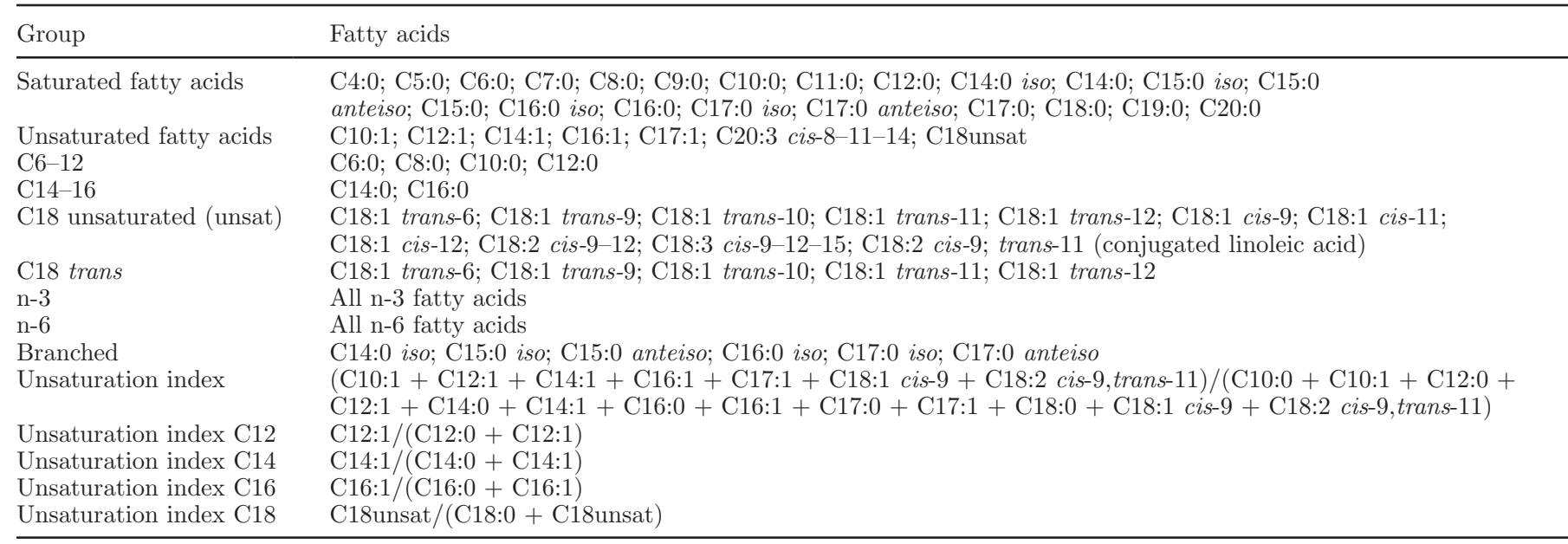

cows were kept indoors during the studied period and milked twice a day with conventional milking systems. From the 3 farms for each breed, 1 or 2 were organic and the other 1 or 2 were conventional (DF, MRY, and GWH 1 organic and 2 conventional, and JER 2 organic and 1 conventional).

Fatty acid composition of milk samples was obtained using GC at the laboratory of Qlip N.V. (Leusden, the Netherlands). The GC outputs were generated by analyzing methyl esters. Fatty acid methyl esters were prepared using fat fractions extracted from the milk, as described in ISO Standard 15884 (ISO-IDF, 2002b). Methyl esters were analyzed, as described in ISO Standard 15885 (ISO-IDF, 2002a), according to the $100 \%$ FA methyl ester method with a 100-m polar column (Varian Fame Select CP 7420, Varian Inc., Palo Alto, $\mathrm{CA})$. The percentages of total fat and total protein were obtained from standard mid-infrared spectrometry using a Fourier-transformed interferogram (MilkoScan FT 6000, Foss Electric, Hillerød, Denmark) at the laboratory of Qlip N.V. (Zutphen, the Netherlands).

In the current study, only the major FA were considered. In total 29 traits were studied: 13 individual major FA, 9 groups of FA, 5 indices, and 2 milk production traits. The 13 individual FA were C4:0, C6:0, C8:0, C10:0, C12:0, C14:0, C16:0, C18:0, C18:1 trans-6, $\mathrm{C} 18: 1$ trans-9, C18:1 trans-10, C18:1 trans-11, and C18:2 cis-9,trans-11 (conjugated linoleic acid; CLA). The 9 groups and 5 indices of FA are reported in Table 1. The 2 milk production traits were fat and protein contents.

Breed differences were estimated using the GLM procedure (SAS Institute Inc., Cary, NC) with the Bonferroni adjustment for multiple comparisons of means. The model, for all traits, was as follows:

$$
\begin{gathered}
y_{i j k l m n o}=\mu+\text { dim }_{i}+\text { parity }_{j}+\text { age }_{k}\left(\text { parity }_{j}\right)+\text { breed }_{l} \\
+ \text { system }_{m}+\text { farm }_{n}\left(\text { breed }_{l} \times \text { system }_{m}\right)+e_{i j k l m n o}
\end{gathered}
$$

where $y_{i j k l m n o}$ is observation ijklmno for the studied variable; $\mu$ is the overall intercept of the model; $\operatorname{dim}_{i}$ is the fixed effect of the $i$ th class of stage of lactation $(6$ classes of $60 \mathrm{~d}$ each, except for the last, which was an open class of $>300 \mathrm{~d}$ ); parity $_{j}$ is the fixed effect of the $j$ th lactation (4 classes: first, second, third, and fourth and later parities); $a g e_{k}\left(\right.$ parity $\left._{j}\right)$ is the fixed effect of the $k$ th class of age at calving within the $j$ th parity (within each parity, 3 classes were defined containing an equal number of cows); breed $_{l}$ is the fixed effect of the $l$ th breed (DF, MRY, GWH, and JER); system $m$ is the fixed effect of the $m$ th farming system (conventional and organic); farm $_{n}\left(\right.$ breed $_{l} \times$ system $\left._{m}\right)$ is the fixed effect of the $n$th farm nested within the $l$ th breed and the $m$ th system; and $e_{i j k l m n o}$ is the random residual for observation ijklnmo. The nested effect was introduced because only one breed was present on each farm and each farm was either conventional or organic. Breed and system were tested on the error term of farm (breed $\times$ system) to verify whether the variation attributed to these effects was significant. Although the distributions of the data of several traits showed a certain level of skewness (range: -1.32 to 1.19 ) and kurtosis (range: -0.51 to $-3.04)$, log-transforming the $y$ variable, which reduced the level of skewness, had no or only a minor effect on the significance of breed differences. To be consistent for all traits, only results of the untransformed data are shown. Furthermore, checking the residuals of the model for the untransformed traits revealed that they were normally distributed, independent, and had equal variances across the range of predicted values (results not shown). 
Table 2. Means and standard deviations of calving age, parity, and DIM for each breed ${ }^{1}$

\begin{tabular}{|c|c|c|c|c|c|c|c|c|}
\hline Item & \multicolumn{2}{|c|}{$\mathrm{DF}(\mathrm{n}=47)$} & \multicolumn{2}{|c|}{$\operatorname{MRY}(\mathrm{n}=52)$} & \multicolumn{2}{|c|}{ GWH $(\mathrm{n}=45)$} & \multicolumn{2}{|c|}{$\operatorname{JER}(\mathrm{n}=46)$} \\
\hline Calving age (d) & 1,566 & 919 & 1,497 & 731 & 1,717 & 958 & 1,805 & 927 \\
\hline DIM (d) & 144 & 112 & 174 & 130 & 160 & 93 & 211 & 132 \\
\hline
\end{tabular}

${ }^{1}$ DF $=$ Dutch Friesian; MRY = Meuse-Rhine-Yssel; GWH = Groningen White Headed; JER = Jersey.

Means and standard deviations of the factors included in the model are reported in Table 2. On average, the MRY animals were somewhat younger (calving age 1,497 d) and in an earlier parity (2.8) compared with the other breeds, and the JER animals were oldest $(1,805 \mathrm{~d})$. Dutch Friesian cows were, on average, shortest in milk (144 d) and JER longest (211 d). The variability of DIM was smallest for the GWH breed (SD: $93 \mathrm{~d}$ ) compared with MRY (SD: $130 \mathrm{~d}$ ) and JER (SD: $132 \mathrm{~d}$ ).
The variation attributed to breed was significant for 15 traits $(P<0.05$; Table 3$)$, and the variation due to system was significant for 5 traits $(P<0.05$; data not shown). The effects of DIM, parity, age at calving, and farm nested within breed and system were not significant for some traits, but they were always included to keep the model consistent. Coefficients of determination ranged from 0.45 (unsaturation index C18; data not shown) to 0.94 (n-3; data not shown). Surprisingly, the coefficient of determination for $n-3$

Table 3. Least squares means of individual fatty acids (FA), groups of fatty acids, indices, and milk production traits for each breed

\begin{tabular}{|c|c|c|c|c|c|c|}
\hline \multirow[b]{2}{*}{ Trait } & \multicolumn{4}{|c|}{ Breed $^{1}$} & \multirow[b]{2}{*}{$\mathrm{SE}$} & \multirow[b]{2}{*}{$P$-value } \\
\hline & $\mathrm{DF}$ & MRY & GWH & JER & & \\
\hline $\mathrm{C} 4: 0$ & $3.82^{\mathrm{a}}$ & $3.65^{\mathrm{ab}}$ & $3.63^{\mathrm{ab}}$ & $3.59^{\mathrm{b}}$ & $0.051-0.058$ & \\
\hline C6:0 & $2.64^{\mathrm{a}}$ & $2.56^{\mathrm{a}}$ & $2.33^{\mathrm{b}}$ & $2.44^{\mathrm{b}}$ & $0.030-0.035$ & * \\
\hline $\mathrm{C} 8: 0$ & $1.59^{\mathrm{a}}$ & $1.52^{\mathrm{a}}$ & $1.32^{\mathrm{b}}$ & $1.39^{\mathrm{b}}$ & $0.024-0.027$ & $* *$ \\
\hline C10:0 & $3.87^{\mathrm{a}}$ & $3.66^{\mathrm{ab}}$ & $2.98^{\mathrm{c}}$ & $3.36^{\mathrm{b}}$ & $0.078-0.090$ & $*$ \\
\hline C16:0 & $30.90^{\mathrm{b}}$ & $29.54^{\mathrm{bc}}$ & $28.98^{\mathrm{c}}$ & $33.64^{\mathrm{a}}$ & $0.386-0.446$ & \\
\hline C18:0 & $10.43^{\mathrm{a}}$ & $10.32^{\mathrm{a}}$ & $10.82^{\mathrm{a}}$ & $10.93^{\mathrm{a}}$ & $0.216-0.250$ & \\
\hline C18:1 trans- 6 & $0.212^{\mathrm{a}}$ & $0.213^{\mathrm{a}}$ & $0.190^{\mathrm{b}}$ & $0.173^{\mathrm{b}}$ & $0.005-0.006$ & \\
\hline C18:1 trans -9 & $0.148^{\mathrm{a}}$ & $0.148^{\mathrm{a}}$ & $0.146^{\mathrm{a}}$ & $0.118^{\mathrm{b}}$ & $0.003-0.004$ & $\dagger$ \\
\hline C18:1 trans -10 & $0.234^{\mathrm{a}}$ & $0.218^{\mathrm{a}}$ & $0.172^{\mathrm{b}}$ & $0.153^{\mathrm{b}}$ & $0.007-0.008$ & $*$ \\
\hline C18:1 trans-11 & $0.704^{\mathrm{c}}$ & $0.975^{\mathrm{b}}$ & $1.25^{\mathrm{a}}$ & $0.898^{\mathrm{b}}$ & $0.028-0.032$ & $* *$ \\
\hline C18:2 cis-9, trans- 11 & $0.297^{\mathrm{c}}$ & $0.413^{\mathrm{b}}$ & $0.570^{\mathrm{a}}$ & $0.313^{\mathrm{c}}$ & $0.011-0.013$ & $* * *$ \\
\hline \multicolumn{7}{|l|}{ Groups of FA (g/100 $\mathrm{g}$ of fat) } \\
\hline$n-3$ & $0.580^{\mathrm{d}}$ & $0.965^{\mathrm{b}}$ & $1.38^{\mathrm{a}}$ & $0.873^{\mathrm{c}}$ & $0.020-0.023$ & \\
\hline $\mathrm{n}-6$ & $1.62^{\mathrm{a}}$ & $1.41^{\mathrm{b}}$ & $1.16^{\mathrm{c}}$ & $1.08^{\mathrm{c}}$ & $0.037-0.043$ & $*$ \\
\hline C18 unsaturated & $20.31^{\mathrm{b}}$ & $21.29^{\mathrm{b}}$ & $23.71^{\mathrm{a}}$ & $19.64^{\mathrm{b}}$ & $0.450-0.520$ & \\
\hline C18 trans & $1.61^{\mathrm{c}}$ & $1.86^{\mathrm{b}}$ & $2.06^{\mathrm{a}}$ & $1.59^{\mathrm{c}}$ & $0.036-0.042$ & $\dagger$ \\
\hline Branched & $1.78^{\mathrm{ab}}$ & $1.87^{\mathrm{a}}$ & $1.74^{\mathrm{b}}$ & $1.56^{\mathrm{c}}$ & $0.024-0.028$ & $t$ \\
\hline \multicolumn{7}{|l|}{ Indices } \\
\hline Unsaturation index & $0.228^{\mathrm{b}}$ & $0.239^{\mathrm{b}}$ & $0.268^{\mathrm{a}}$ & $0.224^{\mathrm{b}}$ & $0.005-0.006$ & $\dagger$ \\
\hline Unsaturation index $\mathrm{C} 12$ & $0.021^{\mathrm{a}}$ & $0.022^{\mathrm{a}}$ & $0.020^{\mathrm{ab}}$ & $0.018^{\mathrm{b}}$ & 0.001 & \\
\hline Unsaturation index C14 & $0.069^{\mathrm{b}}$ & $0.078^{\mathrm{a}}$ & $0.078^{\mathrm{a}}$ & $0.069^{\mathrm{b}}$ & 0.002 & t \\
\hline Unsaturation index C16 & $0.039^{\mathrm{b}}$ & $0.038^{\mathrm{b}}$ & $0.045^{\mathrm{a}}$ & $0.044^{\mathrm{ab}}$ & $0.001-0.002$ & $*$ \\
\hline Unsaturation index C18 & $0.658^{\mathrm{bc}}$ & $0.674^{\mathrm{ab}}$ & $0.690^{\mathrm{a}}$ & $0.640^{\mathrm{c}}$ & $0.005-0.006$ & ** \\
\hline \multicolumn{7}{|l|}{ Production traits } \\
\hline Fat $(\%)$ & $4.73^{\mathrm{b}}$ & $4.63^{\mathrm{b}}$ & $4.53^{\mathrm{b}}$ & $6.16^{\mathrm{a}}$ & $0.111-0.124$ & $*$ \\
\hline
\end{tabular}

${ }^{\mathrm{a}-\mathrm{d}}$ Values with different superscripts within a row indicate significance differences of LSM values at $P<0.05$.

${ }^{1} \mathrm{DF}=$ Dutch Friesian; MRY $=$ Meuse-Rhine-Yssel; GWH $=$ Groningen White Headed; JER $=$ Jersey.

$\dagger P<0.10 ;{ }^{*} P<0.05 ;{ }^{* *} P<0.01 ;{ }^{* * *} P<0.001$. 
was much higher than that for other traits, but no clear explanation could be identified.

Least squares means of individual FA, groups of FA, indices, and production traits for the different breeds are shown in Table 3. An important question is whether these are purely breed effects or are breed-herd effects, because only one breed was sampled per farm. This design of the data may be problematic if (1) the management (e.g., level of feeding) on farms within one or more breeds deviates systematically from that in the average herd (e.g., all herds with breed A feed concentrates, whereas herds with breed B do not feed any concentrates); or (2) within a particular breed, the selected farms are not representative for the breed. Checking the data revealed that the differences in raw averages of milk production traits among breeds within the data set used were comparable to the differences among breeds shown in national milk production statistics, in which JER produces roughly $1.5 \%$ more fat and around $0.5 \%$ more protein than the other breeds. This supports the premise that the selected farms are representative for the different breeds. Because, within breed, at least one conventional and one organic farm were included, which implies a large difference in management and feeding level, a systematic deviation in management among breeds was partly avoided. Although it was not possible to correct completely for rearing conditions, analyzing the variances revealed that the model was at least able to differentiate to a certain level between herd and breed effects for most traits.

The proportion of most FA and groups of FA was significantly different $(P<0.05)$ among breeds (Table 3$)$. Jersey cows produced a significantly higher proportion of saturated FA (SFA; 74.3\%) compared with GWH (68.9\%). The latter breed produced the highest proportion of C18:1 trans-11 (1.25\%) and CLA (0.570\%), and had the highest C18 unsaturation index (0.690). Dutch Friesian cows produced the highest proportion of C6-12 (12.8\%) and JER the highest proportion of C14-16 (45.3\%).

Grazing- or nongrazing-based feeding largely influence milk FA composition (Palmquist et al., 1993; Beaulieu and Palmquist, 1995; Heck et al., 2009). In particular, grazing-based feeding has a negative effect on the proportion of SFA and a positive effect on the proportion of unsaturated FA (Heck et al., 2009). The diet of the sampled cows contained no grazed grass because all cows were kept indoors. This was also the case in the studies of Stoop et al. (2008), Bobe et al. (2007), and Beaulieu and Palmquist (1995).

The average production of $\mathrm{C} 14-16$ of JER cows was $45.3 \%$ (Table 3), which is higher than results from other researches on the same breed: $41.8 \%$ (White et al., 2001), 43.3\% (Stull and Brown, 1964), and 42.8\%
(Beaulieu and Palmquist, 1995). In those studies, JER produced a higher proportion of $\mathrm{C} 14-16$ than HF cows, except in the study of Beaulieu and Palmquist (1995), which reported higher proportions of $\mathrm{C} 14-16$ in $\mathrm{HF}$ milk. The average production of $\mathrm{C} 14-16$ in JER was in the range of 37.45 to $49.47 \%$ that was reported by Carroll et al. (2006). No detailed information on milk fat composition in DF and GWH breeds could be found in other studies. Soyeurt et al. (2006) studied milk fat composition of MRY and JER in Belgium, mainly using data of crossbred animals. In that study, FA profile was based on mid-infrared analysis and the authors reported a lower proportion of total SFA for JER compared with MRY cows, whereas in the current study JER showed the highest proportion of SFA in milk. However, in the same study, the difference in unsaturation index for C16:0 was in agreement with that in the current study. Although the total amount of CLA, which is associated with positive health effects, was generally low, the breed effect was found significant $(P<0.001)$. Significant breed differences for CLA were also reported in Lawless et al. (1999), where the Montbéliarde cows produced higher proportions of CLA (1.99\%) compared with the Dutch HF cows (1.76\%). In another study including 1,918 Dutch HF cows (Stoop et al., 2008), the proportion of CLA was reported to be, on average, $0.39 \%$. The samples of this large study were taken during the indoor season between February and March, which is comparable with the current study, but the cows were all within first lactation. For C14-16, Stoop et al. (2008) reported an average proportion of $44.2 \%$, which is almost as high as the JER in current study. Other studies including the HF breed reported C14-16 proportions of $32.4 \%$ (Mele et al., 2009), 39.1 to $39.5 \%$ (Bobe et al., 2007), 44.0\% (Beaulieu and Palmquist, 1995), and 36.5\% (Lawless et al., 1999).

In conclusion, our results suggest that the Dutch cattle breeds have some favorable milk composition characteristics. First, the local MRY and GWH breeds produced smaller proportions of $\mathrm{C} 14-16$ than the mainstream JER. Second, the proportion of n-3 was higher in MRY and GWH. Third, the GWH cows produced higher proportions of CLA and unsaturated FA. Therefore, the study seems to reveal characteristics of the local Dutch breeds that support the need to conserve them. These results can be used to promote the use of particular breeds and suggests that the genetic features of a population in favor of human health can be modified permanently by making use of the different breeds in the dairy cattle population. However, the results should be confirmed in a larger study in which the breeds compared are held on the same farms and thus exposed to the same production environment. 


\section{ACKNOWLEDGMENTS}

This study was financially supported by the Ministry of Agriculture, Nature and Food (Programme "Kennisbasis Research;" KB-04-002-021 and KB-05-003-041). Johan van Arendonk and Henk Bovenhuis (Wageningen University, Animal Breeding and Genomics Center, Wageningen, the Netherlands), as well as Mari Smits and Roel Veerkamp (Wageningen UR Livestock Research, Animal Breeding, and Genomics Center, Lelystad, the Netherlands) are thanked for comments on the set-up of this study. The 12 involved farmers are thanked for contributing milk samples to this study.

\section{REFERENCES}

Beaulieu, A. D., and D. L. Palmquist. 1995. Differential effects of high fat diets on fatty acid composition in milk of Jersey and Holstein cows . J. Dairy Sci. 78:1336-1344.

Bobe, G., G. L. Lindberg, A. E. Freeman, and D. C. Beitz. 2007. Short communication: Composition of milk protein and milk fatty acids is stable for cows differing in genetic merit for milk production. J. Dairy Sci. 90:3955-3960.

Carroll, S. M., E. J. DePeters, S. J. Taylor, M. Rosenberg, H. PerezMonti, and V. Capps. 2006. Milk composition of Holstein, Jersey, and Brown Swiss cows in response to increasing levels of dietary fat. Anim. Feed Sci. Technol. 131:451-473.

CRV. 2009. Jaarstatistieken 2008. CRV, Arnhem, the Netherlands.

Dalvit, C., M. De Marchi, and M. Cassandro. 2007. Genetic traceability of livestock products: A review. Meat Sci. 77:437-449.

European Cattle Genetic Diversity Consortium. 2006. Marker-assisted conservation of European cattle breeds: An evaluation. Anim. Genet. 37:475-481.

German, J. B., and C. J. Dillard. 2006. Composition, structure and absorption of milk lipids: A source of energy, fat-soluble nutrients and bioactive molecules. Crit. Rev. Food Sci. Nutr. 46:57-92.

Heaney, R. P. 2000. Calcium, dairy products and osteoporosis. J. Am. Coll. Nutr. 19:83S-99S.

Heck, J. M. L., H. J. F. van Valenberg, J. Dijkstra, and A. C. M. van Hooijdonk. 2009. Seasonal variation in the Dutch bovine raw milk composition. J. Dairy Sci. 92:4745-4755.

ISO-IDF. 2002a. Milkfat-Determination of the fatty acid composition by gas-liquid chromatography. ISO 15885-IDF 184. International Dairy Federation, Brussels, Belgium.
ISO-IDF. 2002b. Milkfat-Preparation of fatty acid methyl ester. ISO 15884-IDF 184. International Dairy Federation, Brussels, Belgium.

Lawless, F., C. Stanton, P. L'Escop, R. Devery, P. Dillon, and J. J. Murphy. 1999. Influence of breed on bovine milk cis-9, trans-11conjugated linoleic acid content. Livest. Prod. Sci. 62:43-49.

Lock, A. L., and D. E. Bauman. 2004. Modifying milk fat composition of dairy cows to enhance fatty acids beneficial to human health. Lipids 39:1197-1206.

Mele, M., R. Dal Zotto, M. Cassandro, G. Conte, A. Serra, A. Buccioni, G. Bittante, and P. Secchiari. 2009. Genetic parameters for conjugated linoleic acid, selected milk fatty acids, and milk fatty acid unsaturation of Italian Holstein-Friesian cows. J. Dairy Sci. 92:392-400.

Neumann, C. G., N. O. Bwibo, S. P. Murphy, M. Sigman, S. Whaley, L. H. Allen, D. Guthrie, R. E. Weiss, and M. W. Demment. 2003 Animal source foods improve dietary quality, micronutrient status, growth and cognitive function in Kenyan school children: Background, study design and baseline findings. J. Nutr. 133:3941S3949S.

Palmquist, D. L. 2006. Milk fat: Origin of fatty acids and influence of nutritional factors thereon. Pages 43-92 in Advanced Dairy Chemistry. Vol. 2. Lipids. 3rd ed. P. F. Fox and P. L. H. McSweeney, ed. Springer, New York, NY.

Palmquist, D. L., A. D. Beaulieu, and D. M. Barbano. 1993. Feed and animal factors influencing milk-fat composition. J. Dairy Sci. 76:1753-1771.

Palmquist, D. L., K. Stelwagen, and P. H. Robinson. 2006. Modifying milk composition to increase use of dairy products in healthy diets - Preface. Anim. Feed Sci. Technol. 131:149-153.

Pretto, D., M. De Marchi, C. Dalvit, and M. Cassandro. 2009. Comparing profitability of Burlina and Holstein Friesian cattle breeds. Ital. J. Anim. Sci. 8(Suppl. 3):65-67.

Soyeurt, H., P. Dardenne, A. Gillon, C. Croquet, S. Vanderick, P. Mayeres, C. Bertozzi, and N. Gengler. 2006. Variation in fatty acid contents of milk and milk fat within and across breeds. J. Dairy Sci. 89:4858-4865.

Stoop, W. M., J. A. M. van Arendonk, J. M. L. Heck, H. J. F. van Valenberg, and H. Bovenhuis. 2008. Genetic parameters for major milk fatty acids and milk production traits of Dutch HolsteinFriesians. J. Dairy Sci. 91:385-394.

Stull, J. W., and W. H. Brown. 1964. Fatty acid composition of milk. II. Some differences in common dairy breeds. J. Dairy Sci. 47:1412.

Uauy, R. 2009. Dietary fat quality for optimal health and well-being: Overview of recommendations. Ann. Nutr. Metab. 54:2-7.

White, S. L., J. A. Bertrand, M. R. Wade, S. P. Washburn, J. T. Green, and T. C. Jenkins. 2001. Comparison of fatty acid content of milk from Jersey and Holstein cows consuming pasture or a total mixed ration. J. Dairy Sci. 84:2295-2301. 